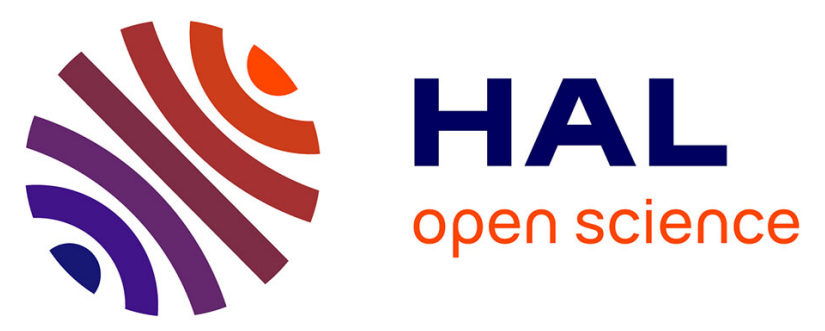

\title{
Synthetic Method Dependent Physicochemical Properties and Electrochemical Performance of Ni-Doped $\mathrm{ZnO}$
}

\author{
A Chandrasekaran, Thibeorchews Prasankumar, Sujin P Jose, Kandasamy \\ Anitha, Craig Ekstrum, Joshua Pearce, Jeyanthinath Mayandi, \\ Chandrasekaran Abinaya
}

\section{To cite this version:}

A Chandrasekaran, Thibeorchews Prasankumar, Sujin P Jose, Kandasamy Anitha, Craig Ekstrum, et al.. Synthetic Method Dependent Physicochemical Properties and Electrochemical Performance of Ni-Doped ZnO. ChemistrySelect, 2017, 2 (28), pp.9014-9023. 10.1002/slct.201701584 . hal-02111396

\section{HAL Id: hal-02111396 https://hal.science/hal-02111396}

Submitted on 26 Apr 2019

HAL is a multi-disciplinary open access archive for the deposit and dissemination of scientific research documents, whether they are published or not. The documents may come from teaching and research institutions in France or abroad, or from public or private research centers.
L'archive ouverte pluridisciplinaire HAL, est destinée au dépôt et à la diffusion de documents scientifiques de niveau recherche, publiés ou non, émanant des établissements d'enseignement et de recherche français ou étrangers, des laboratoires publics ou privés. 
A. Chandrasekaran, T. Prasankumar, Sujin P Jose, K. Anitha, C. Ekstrum, J. M. Pearce, J. Mayandi. "Synthetic method dependent physicochemical properties and electrochemical performance of Ni doped ZnO”, Chemistry Select 2(28), 2017, pp. 9014-9023. doi:

https://doi.org/10.1002/slct.201701584

\title{
Synthetic method dependent physico-chemical properties and electrochemical performance of $\mathrm{Ni}$ doped $\mathrm{ZnO}$
}

A. Chandrasekaran, ${ }^{\text {a }}$, T. Prasankumar ${ }^{\mathrm{b}}$, Sujin P Jose ${ }^{\mathrm{b}, \mathrm{c}}$, K. Anitha ${ }^{\mathrm{d}}$, C. Ekstrum ${ }^{\mathrm{e}}$, J. M. Pearce ${ }^{\mathrm{e}, \mathrm{f}}$, J. Mayandi*a, e

${ }^{a}$ Department of Materials Science, School of Chemistry, Madurai Kamaraj University, Madurai- 625 021, Tamil Nadu, India.

${ }^{\mathrm{b}}$ Department of Computational Physics, School of Physics, Madurai Kamaraj University, Madurai 625 021, Tamil Nadu, India.

${ }^{\mathrm{c}}$ Department of Materials Science and Nano Engineering, Rice University, Houston- 77005, Texas, USA.

${ }^{d}$ Department of Physics, School of Physics, Madurai Kamaraj University, Madurai - 625 021, Tamil Nadu, India.

${ }^{\mathrm{e}}$ Department of Materials Science and Engineering, Michigan Technological University, Houghton 49931, Michigan, USA.

${ }^{\mathrm{f}}$ Department of Electrical \& Computer Engineering, Michigan Technological University, Houghton 49931, Michigan, USA.

\begin{abstract}
Nickel doped zinc oxide $(\mathrm{Ni} / \mathrm{ZnO})$ nanostructures have the potential to improve the performance of electrochemical capacitors. This study investigates the preparation of $\mathrm{Ni} / \mathrm{ZnO}$ nanomaterials by facile co-precipitation (CPM) and hydrothermal (HTM) methods. The effect of the synthesis methods on the optical, structural, chemical and morphological properties on $\mathrm{ZnO}$ products is investigated using ultra violet (UV)-visible spectroscopy, X-ray diffraction (XRD), field emission scanning electron microscopy (FESEM), X-ray spectrometry (EDX), room temperature photoluminescence (PL), Fourier transform infrared (FTIR) and Raman spectroscopy. Finally, the electrochemical performance of the synthesized nanorods were examined by fabrication of a supercapacitor using standard three electrode cell configuration and tested with a cyclic voltammogram (CV) and galvanostatic chargedischarge (GCD) measurements. The results shown that the samples synthesized by HTM exhibited improved electrochemical capacitance performance with higher current density. The discharge curves are linear in the total range of potential with constant slopes, showing perfect capacitance. In conclusion, $\mathrm{Ni} / \mathrm{ZnO}$ nanoparticles synthesized by this method with further optimization have the potential to lead to a high-efficiency supercapacitors.
\end{abstract}

Keywords: zinc oxide, $\mathrm{Ni}$ doped $\mathrm{ZnO}$, co precipitation method, hydrothermal synthesis, electrochemical performance

\section{Introduction}

Zinc oxide $(\mathrm{ZnO})$ nanostructures have drawn significant scientific interest because of its characteristic features and novel application in various fields [1-7]. $\mathrm{ZnO}$ is a contender for the next generation devices because of its unique opto-electronic properties that include a large band gap $(\sim 3.3 \mathrm{eV}$ at room temperature), higher values of breakdown voltages (higher than Carbon nanotubes)[8], sustaining large electric fields, high quantum efficiency, higher exciton energy, hightemperature and high-power operations $[\mathbf{9 , 1 0 ]}$. $\mathrm{ZnO}$ seems to have the richest varieties of nanostructures such as wires [11], tubes [12], rods [13], belts [14], rings [15], springs [16], combs [17], flowers [18], and peanuts shapes [19]. Numerous methods have been reported for the preparation of nanostructures including precipitative methods (usually aqueous and at low temperature) [20, 21], reactive methods in high boiling point solvents [22], hydrothermal and solvothermal methods [23], and vapour phase reactions [24]. Among them co-precipitation (CPM) and hydrothermal (HTM) method have been acknowledged as an effective route for the synthesis of nanostructures for the reason that they are simple, non-hazardous, high yielding and economic. In CPM synthesis a solute that remain dissolved in a solution precipitates out on a carrier that forces it to bind together, rather than remaining dispersed [25]. It includes three mechanisms such as inclusion, occlusion, and adsorption. In contrast, hydrothermal synthesis is a precise method for crystallizing 
A. Chandrasekaran, T. Prasankumar, Sujin P Jose, K. Anitha, C. Ekstrum, J. M. Pearce, J. Mayandi. "Synthetic method dependent physicochemical properties and electrochemical performance of Ni doped ZnO”, Chemistry Select 2(28), 2017, pp. 9014-9023. doi: https://doi.org/10.1002/slct.201701584

substances from high-temperature aqueous solutions at high vapour pressures. A large number of oxide nanoparticles have been synthesized under hydrothermal conditions [26]. The foremost three mechanisms are hydrolysis, oxidation and thermolysis [27].

Due to the presence of intrinsic defects such as oxygen vacancies $(\mathrm{V})$, zinc vacancies $\left(\mathrm{V}_{\mathrm{Zn}}\right)$ and zinc interstials $\left(\mathrm{Z}_{\text {in }}\right)$ the inherent properties of $\mathrm{ZnO}$ do not meet the preferred standard for industrial applications. The $\mathrm{ZnO}$ properties can be improved by doping with selected elements. The transition metal doping in semiconductor $\mathrm{ZnO}$ facilitates the generation of carrier mediated ferromagnetism [28]. In specific, nickel is considered to be the most capable transition metal dopant due to its high chemical stability and exceptional ability to tune electrical, optical and magnetic behaviour of $\mathrm{ZnO}$ nanostructures [29]. Electrochemical capacitors, which have recently received great attention due to their higher power density and higher specific energy than conventional batteries and capacitors [30]. In general, carbon materials, metal oxides and conducting polymers are used as electrodes and among the transition metal oxides ruthenium oxide has the highest efficiency [31] but due to its cost it has not been commercialized. In order to replace the expensive electrodes, nickel oxide, zinc oxide, manganese oxide and cobalt oxide are widely used because of their pseudocapacitive behaviour [32]. Also the dopants such as $\mathrm{Ni}, \mathrm{Co} \mathrm{Mn}$ in $\mathrm{ZnO}$ were extensively studied for various applications such as magnetic, antibacterial, sensors etc., synthesized with simple chemical methods [33-36]. Recently, $\mathrm{ZnO}$ with composites such as $\mathrm{ZnS}$, Ni [New ref 1] and some transition metals Al, Co [New ref 2], Fe [New ref 3], Mn [New ref 4] have attained high specific capacity, cycle durability, stable reversible capacity and high lithium storage capacities [New ref 4]. Although $\mathrm{ZnO}$ exhibits superior physical properties as battery active material with higher energy density and high efficiency, a very few work has been reported in supercapacitor applications [33]. The main cause for this problem is the formation of dendrites during consecutive cycles which lead to the decrease in cycle life [34]. Because of its good electrochemical and eco-friendly nature the reported work investigates merging the properties of $\mathrm{Ni}$ and $\mathrm{ZnO}$ by doping. Quite a few methods have been reported for the synthesis of rod shaped $\mathrm{Ni}$ doped $\mathrm{ZnO}[35,36]$.

This work is focused on the preparation of $\mathrm{Ni} / \mathrm{ZnO}$ nanomaterials by facile co-precipitation and hydrothermal synthesis. The effect of the synthesis routes on the optical, structural, chemical and morphological properties on $\mathrm{ZnO}$ is quantified. The electrochemical performance of the synthesized nanorods were examined by the fabricated supercapacitor electrodes using a standard three electrode cell configuration.

\section{Experimental Procedure}

\subsection{Materials}

Zinc acetate dihydrate, sodium hydroxide, nickel (II) nitrate hexahydrate were purchased from Merck with 98\%, 97\% and 97\% purity, respectively. Distilled water was used as the solvent and all the chemicals were used without further refining.

\subsection{Characterization Techniques}

The crystal structure of the $\mathrm{ZnO}$ nanocrystals was determined by a Bruker X-ray diffractometer (Model AXS D8 Advance using Cu Wavelength $0.1546 \mathrm{~nm}$ ). The morphological features were recorded by Hitachi S-4700 FESEM and an elemental composition was obtained using an FEI Philips XL energy-dispersive X-ray spectrometer. The optical absorption and emission spectra of $\mathrm{ZnO}$ dispersed in distilled water were recorded using Agilent $8453 \mathrm{UV}$-Visible spectrophotometer and Agilent spectrofluorometer carry eclipse. The FT-IR spectra of the sample were obtained with a Thermo Nicolet 6700 and Raman scattering measurements were performed using Horiba Jobin Yvon Lab Ram HR800 equipped with a CCD detector. All the electrochemical measurements were carried out using Bio-Logic (SP-50) electrochemical workstation.

\subsection{Synthesis by Co-Precipitation Method}

Initially, $3 \mathrm{~g}$ of zinc acetate dihydrate and $5 \mathrm{wt} \%$ of nickel (II) nitrate hexahydrate was dissolved in $75 \mathrm{ml}$ of double distilled water and kept stirring for $15 \mathrm{~m}$. Sodium hydroxide solution 
A. Chandrasekaran, T. Prasankumar, Sujin P Jose, K. Anitha, C. Ekstrum, J. M. Pearce, J. Mayandi. "Synthetic method dependent physicochemical properties and electrochemical performance of Ni doped ZnO”, Chemistry Select 2(28), 2017, pp. 9014-9023. doi:

https://doi.org/10.1002/slct.201701584

had been prepared separately by dissolving $2.4 \mathrm{~g}$ of $\mathrm{NaOH}$ in $75 \mathrm{ml}$ of double distilled water. The prepared $\mathrm{NaOH}$ solution was added drop-wise into the initial precursor solution under constant stirring at room temperature. The mixed solution was kept under stirring for $30 \mathrm{~m}$. The gelatinous precipitates was then kept on the hot plate at a temperature of $80^{\circ} \mathrm{C}$ for $5 \mathrm{~h}$. After that the solution was washed with distilled water and ethanol for several times using a centrifuge. The final precipitate was collected and dried at $120^{\circ} \mathrm{C}$ by means of hot plate for $1 \mathrm{~h}$ in atmosphere.

\subsection{Synthesis by Hydrothermal Method}

In this method, $3 \mathrm{~g}$ of zinc acetate dihydrate was dissolved in $75 \mathrm{ml}$ of double distilled water with $5 \mathrm{wt} \%$ of $\mathrm{Ni}\left(\mathrm{NO}_{3}\right)_{2} \cdot 6 \mathrm{H}_{2} \mathrm{O}$. The buffer solution was prepared by taking $2.4 \mathrm{~g}$ of $\mathrm{NaOH}$ in $75 \mathrm{ml}$ of distilled water. This solution was added drop by drop to the Ni doped $\mathrm{Zn}$ solution under stirring. The initial solution containing milky coloured precipitate was kept for stirred for $30 \mathrm{~m}$. The resulting solution was kept in an autoclave and placed inside a muffle furnace at a temperature of $160^{\circ} \mathrm{C}$ for 5 $\mathrm{h}$. The obtained precipitate was then washed with distilled water and ethanol 3 times respectively and dried at $120^{\circ} \mathrm{C}$ for $1 \mathrm{~h}$ using hot plate.

\subsection{Fabrication of electrode}

The working electrode was prepared by mixing of $80 \mathrm{wt} \%$ of $\mathrm{Ni} / \mathrm{ZnO}$ as active material, 15 wt $\%$ of acetylene black as conducting agent and $5 \mathrm{wt} \%$ of PVDF (polyvinylidene fluoride) as binder with few drops of n-methylpyrrolidone (NMP) as solvent. The prepared slurry was pasted onto a pre cleaned carbon felt. The substrate was dried at $100^{\circ} \mathrm{C}$ for $12 \mathrm{hrs}$ which was then employed as working electrode.

\subsection{Electrochemical Tests}

Supercapacitor behaviour of the $\mathrm{Ni} / \mathrm{ZnO}$ nanoparticles was studied using $\mathrm{CV}$ and GCD measurements. The electrochemical properties of the samples were carried out using three electrode cell configurations with $\mathrm{Ni} / \mathrm{ZnO}$ electrode as the working electrode, $\mathrm{Ag} / \mathrm{AgCl}$ as the reference electrode while a platinum wire as the counter electrode. $1 \mathrm{M} \mathrm{KOH}$ aqueous solution was used as the electrolyte.

\section{Result and Discussion}

\subsection{XRD}



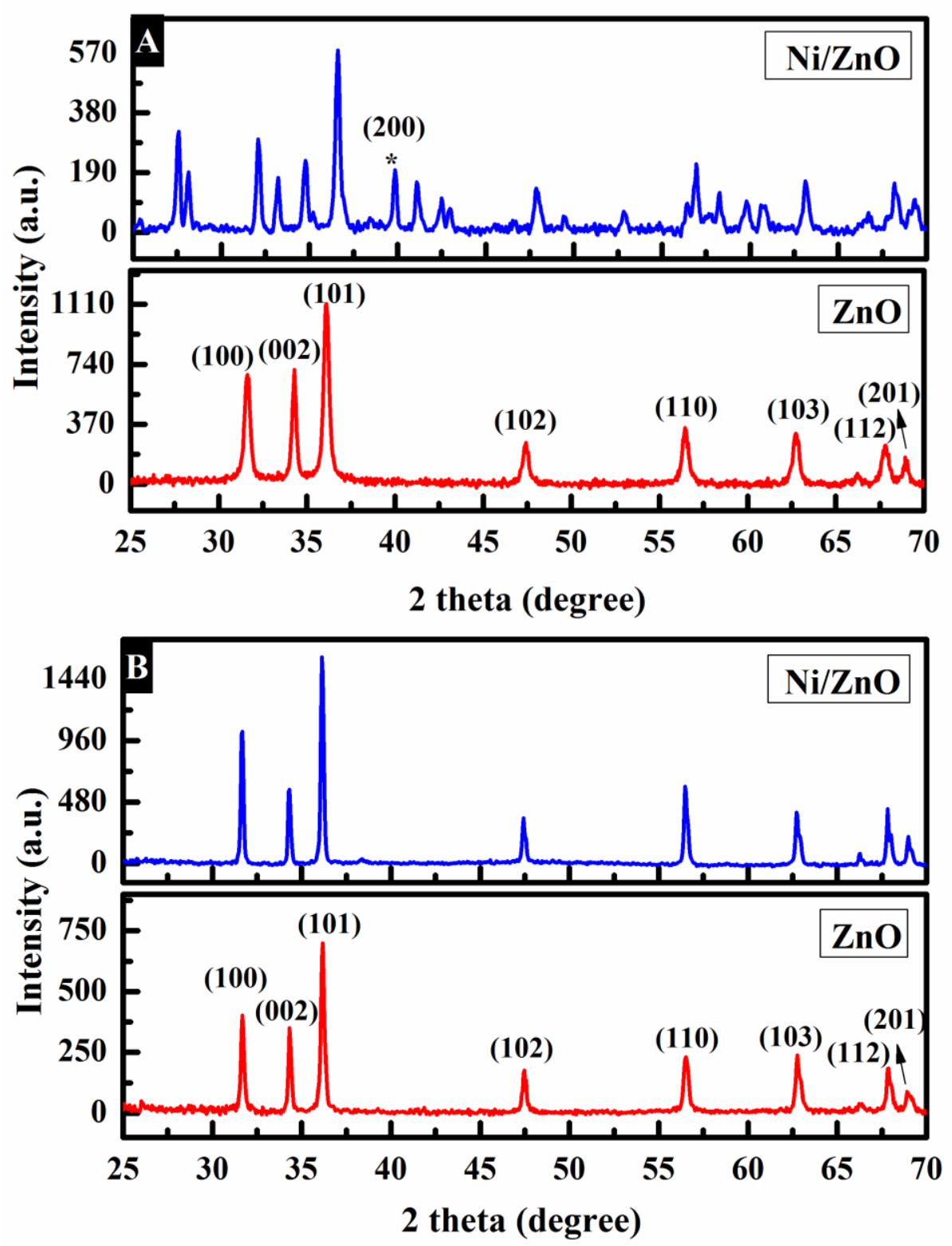

Figure 1 Powder diffraction pattern of pure and $\mathrm{Ni} / \mathrm{ZnO}$ nanoparticles synthesized by CPM (A) and HTM (B) (*indicates the presence of Ni).

Figure 1 (A) and (B) depicts the XRD pattern of pure and $\mathrm{Ni}$ doped $\mathrm{ZnO}$ nanoparticles prepared by co-precipitation and hydrothermal method in the range from $25^{\circ}$ to $70^{\circ}$. The peaks observed in the XRD pattern confirm the polycrystalline nature of the nanoparticle, with (100), (002), (101), (102), (110), (103), (112) and (201) reflections of pure $\mathrm{ZnO}$ phase with the hexagonal wurtzite structure (JCPDS card No. 89-0510). Altogether the reflections were highly oriented along the most stable phase (101) of $\mathrm{ZnO}$ and it is used for further calculations. In Figure 1 (A) an additional peak at $43.29^{\circ}$ was observed and it can be indexed for the (200) reflection of nickel oxide (NiO). It shows that the $\mathrm{Ni} / \mathrm{ZnO}$ was formed along with the $\mathrm{NiO}$ phase and its noteworthy this secondary phase was exhibited only by the nickel doped $\mathrm{ZnO}$ prepared by CPM. El-hilo et al., have reported that $4.3 \%$ of $\mathrm{Ni}$ doped $\mathrm{ZnO}$ nano-particles exhibited $\mathrm{NiO}$ phases [37]. The additional peaks observed in the $\mathrm{Ni} / \mathrm{ZnO}$ by CPM were attributed to the presence of zinc hydroxide (JCPDS card No. 01-0360). Diffraction peaks corresponding to $\mathrm{NiO}$ or impurities were not observed in the XRD patterns of 
A. Chandrasekaran, T. Prasankumar, Sujin P Jose, K. Anitha, C. Ekstrum, J. M. Pearce, J. Mayandi. "Synthetic method dependent physicochemical properties and electrochemical performance of Ni doped ZnO”, Chemistry Select 2(28), 2017, pp. 9014-9023. doi:

https://doi.org/10.1002/slct.201701584

HTM, confirming the high purity of synthesized product [38]. Table 1 shows the average crystallite sizes of the samples calculated by Debye Scherrer's equation (equation 1)

$$
D=(0.9 \lambda) /(\beta \cos \theta)
$$

Where, $\mathrm{D}$ is the diameter of the crystallite, $\lambda$ is the wavelength of $\mathrm{Cu} \mathrm{K \alpha}$ line (1.5406 $\AA$ ), $\beta$ is the full width at half maximum (FWHM) in radians and $\theta$ is the Bragg angle.

\begin{tabular}{|c|c|c|c|c|c|}
\hline \multicolumn{2}{|c|}{ Parameters } & \multicolumn{2}{|c|}{$\mathrm{ZnO}$} & \multicolumn{2}{|c|}{$\mathrm{Ni} / \mathrm{ZnO}$} \\
\hline & & CPM & HTM & CPM & HTM \\
\hline \multicolumn{2}{|c|}{ D Spacing $(\AA)$} & 2.488 & 2.481 & 2.455 & 2.483 \\
\hline \multirow[t]{2}{*}{ Lattice Constants (̊̊) } & $\mathbf{a}$ & 3.270 & 3.259 & 3.254 & 3.262 \\
\hline & c & 5.328 & 5.266 & 5.236 & 5.282 \\
\hline \multicolumn{2}{|c|}{ Bond Length $L(\AA)$} & 2.00 & 1.98 & 1.98 & 1.99 \\
\hline \multirow{2}{*}{$\begin{array}{l}\text { Grain Size } \\
\quad(\mathbf{n m})\end{array}$} & 101 Plane & 24 & 38 & 30 & 49 \\
\hline & Average & 25 & 36 & 39 & 47 \\
\hline \multicolumn{2}{|c|}{ Dislocation Density $10^{-3}\left(\mathrm{~nm}^{-2}\right)$} & 1.585 & 0.778 & 0.719 & 0.524 \\
\hline \multicolumn{2}{|c|}{ Micro Strain } & 0.0014 & 0.0009 & 0.0011 & 0.0007 \\
\hline \multicolumn{2}{|c|}{ Volume of unit cell $(\AA)^{3}$} & 49.368 & 48.609 & 45.044 & 48.690 \\
\hline \multicolumn{2}{|c|}{ Net Lattice Distortion } & 0.0052 & 0.0026 & -0.0081 & 0.0032 \\
\hline
\end{tabular}

Table 1. XRD parameters of the pure and $\mathrm{Ni} / \mathrm{ZnO}$ samples by CPM and HTM

The larger size $(47 \mathrm{~nm})$ was observed for the $\mathrm{Ni}$ doped $\mathrm{ZnO}$ nanoparticles synthesized by HTM. Table 2 shows the particle size and strain of pure and $\mathrm{Ni}$ doped $\mathrm{ZnO}$. Compared to the coprecipitation method, the hydrothermally synthesized samples exhibited the highest grain size values. The similar ionic radii 0.74 for $\mathrm{Zn}^{2+}$ and $0.69 \AA$ for $\mathrm{Ni}^{2+}[39-41]$, the substitution of $\mathrm{Ni}^{2+}$ for $\mathrm{Zn}^{2+}$ doesn't result in noticeable lattice distortion and there was no shift observed in the diffraction peaks except for the intensity changes in doped samples.

\begin{tabular}{|c|c|c|c|c|}
\hline \multirow{2}{*}{ Sample Name } & \multicolumn{2}{|c|}{ Particle size (nm) } & \multicolumn{2}{c|}{ Strain } \\
\cline { 2 - 5 } & CPM & HTM & CPM & HTM \\
\hline Pure ZnO & 43 & 110 & 0.00109 & 0.00155 \\
\hline Ni/ZnO & 67 & 112 & 0.00154 & 0.00112 \\
\hline
\end{tabular}

Table 2. Particle size and strain of the pure and $\mathrm{Ni} / \mathrm{ZnO}$ samples by CPM and HTM

\subsection{FE-SEM Analysis}


A. Chandrasekaran, T. Prasankumar, Sujin P Jose, K. Anitha, C. Ekstrum, J. M. Pearce, J. Mayandi. "Synthetic method dependent physicochemical properties and electrochemical performance of Ni doped ZnO”, Chemistry Select 2(28), 2017, pp. 9014-9023. doi: https://doi.org/10.1002/slct.201701584

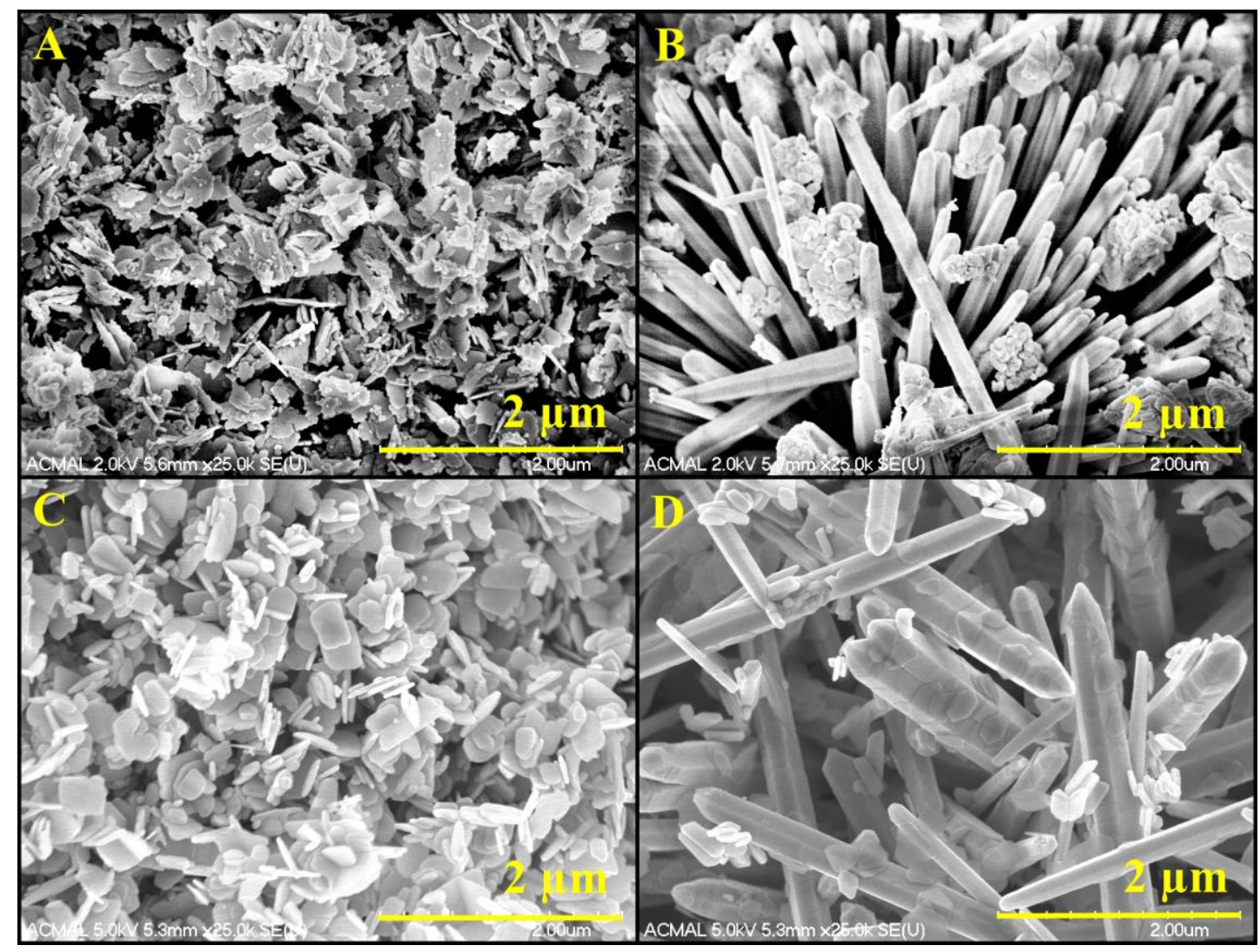

Figure 2 Morphology of pure $\mathrm{ZnO}$ by CPM (A), Ni/ZnO by CPM (B), pure $\mathrm{ZnO}$ by HTM (C) and $\mathrm{Ni} / \mathrm{ZnO}$ by HTM (D)

The morphology of the pure and $\mathrm{Ni} / \mathrm{ZnO}$ synthesized by CPM (A, B) and HTM (C, D) are shown in Figure 2. The pure ZnO's were observed as nanoplates, which were influenced by Ni to form as nanorods, with the absence of any porosity. Both CPM and HTM nanorods were randomly arranged and aligned in small stacks. The pure $\mathrm{ZnO}$ and $\mathrm{Ni} / \mathrm{ZnO}(\mathrm{C} \& \mathrm{D})$ by HTM shows the respective morphologies as nanoplates and nanorods. These morphologies are similar to those produced through CPM. The nanoplates produced by HTM have smoother edges than those from CPM, and have fewer small platelets attached to their faces. HTM nanorods tend to be thicker than those produced by CPM. Some free nanoplates are present in both the nanorod images (B and D). However, the platelets are distributed differently. Comparing with HTM, samples produced by CPM show densely packed with agglomerated particles, distributed throughout the structure. In HTM samples, the nanoplates tend to be more aligned, their faces being parallel, and are affixed to the flat faces of the nanorods. Noting the shape of the nanoplates between the Ni-doped $\mathrm{ZnO}$ and the undoped $\mathrm{ZnO}$, the HTM nanoplates affixed to the nanorods appear to be more hexagonal than the undoped variety. It is clear that $\mathrm{Ni}$ influence the formation of nanorods with narrow tipped prismatic hexagonal surfaces. It is interesting to note the horizontal streaks, and steps, perpendicular to the axis of the nanorods. This feature is more apparent in the HTM-nanorods than the CPM-nanorods, which may only be an artefact of image quality. These lamellar lines supports the claim that the nanorods are indeed stacks of nanoplates, and have been influenced to align around an axis. The diameter of the nanorods slightly but gradually decreases towards the end of the tip. It is reasonable to assume that the incorporation of external impurity into the lattice of $\mathrm{ZnO}$ without altering the overall structure may cause the formation of rods and agglomeration. Experimental conditions in both the methods affect the morphology and size of growing crystal.

Figure $3(\mathrm{~A} \& \mathrm{~B})$ shows a representative EDAX pattern and the details of the relevant elemental analysis for $\mathrm{Ni} / \mathrm{ZnO}$ by CPM (A) and HTM (B). 
A. Chandrasekaran, T. Prasankumar, Sujin P Jose, K. Anitha, C. Ekstrum, J. M. Pearce, J. Mayandi. "Synthetic method dependent physicochemical properties and electrochemical performance of Ni doped ZnO”, Chemistry Select 2(28), 2017, pp. 9014-9023. doi: https://doi.org/10.1002/slct.201701584
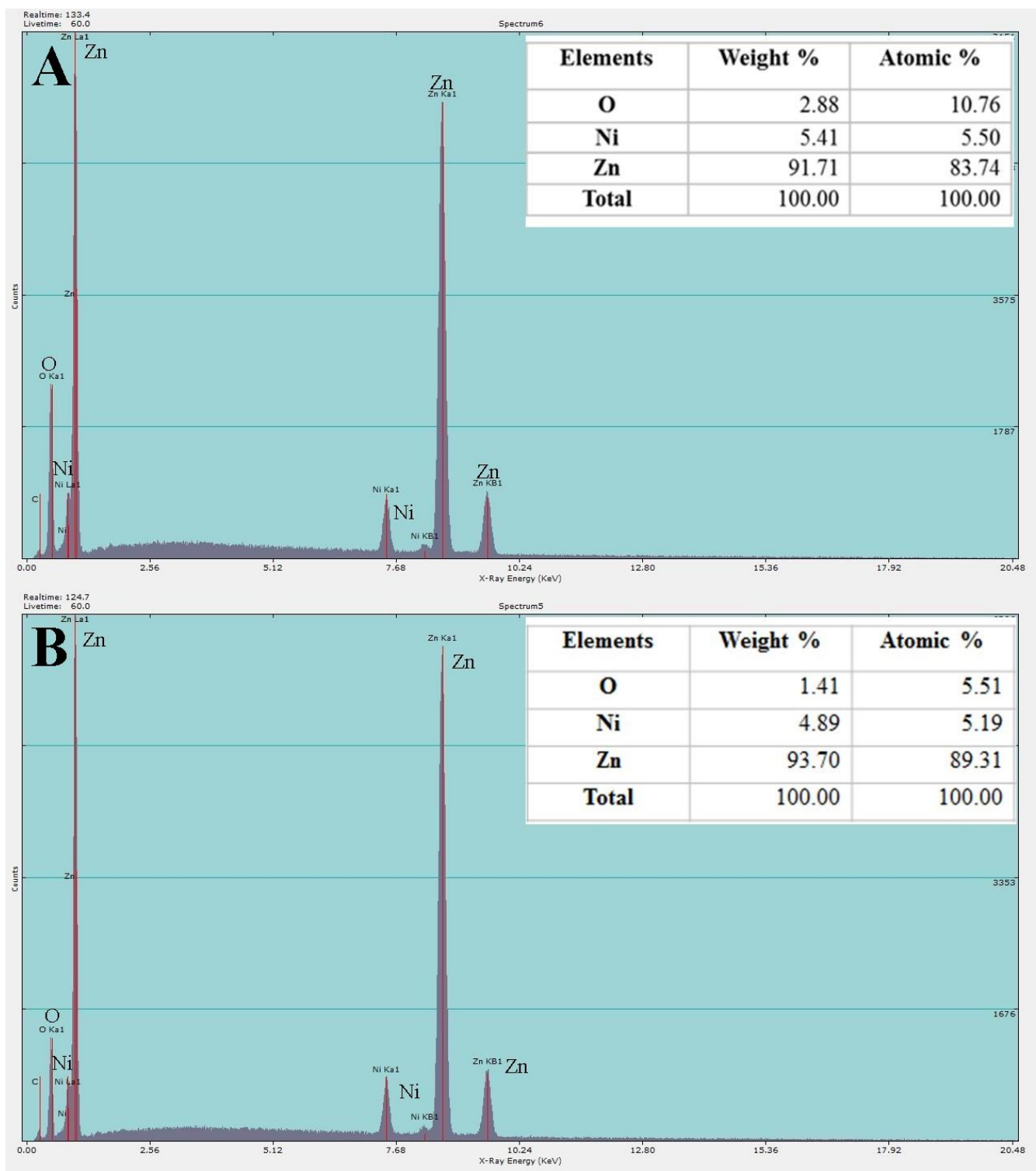

Figure 3 Elemental composition of $\mathrm{Ni} / \mathrm{ZnO}$ by CPM (A), Ni/ZnO by HTM (B)

The pattern shows strong $\mathrm{Zn}$ and $\mathrm{O}$ peaks without any impurity confirming the purity of the samples. The presence of $\mathrm{Ni}$ confirms that $\mathrm{Ni}$ ions were doped into $\mathrm{ZnO}$ nanostructures. Also notable is the difference in oxygen content, between the CPM and HTM samples: The CPM sample contains more oxygen. EDAX also measures more Ni content in the CPM sample, at $5.41 \mathrm{wt} \%$, than the HTM sample, which is measured to have $4.89 \mathrm{wt} \% \mathrm{Ni}$, which corresponds to heavier doping of the CPM sample.

\subsection{UV-Visible Spectral Analysis}

The UV-visible absorption spectra of the as-prepared co-precipitation and hydrothermally synthesized pure $\mathrm{ZnO}$ and $\mathrm{Ni} / \mathrm{ZnO}$ with different morphology was examined and shown in Figure 4 (A) and (B). 
A. Chandrasekaran, T. Prasankumar, Sujin P Jose, K. Anitha, C. Ekstrum, J. M. Pearce, J. Mayandi. "Synthetic method dependent physicochemical properties and electrochemical performance of Ni doped ZnO”, Chemistry Select 2(28), 2017, pp. 9014-9023. doi:
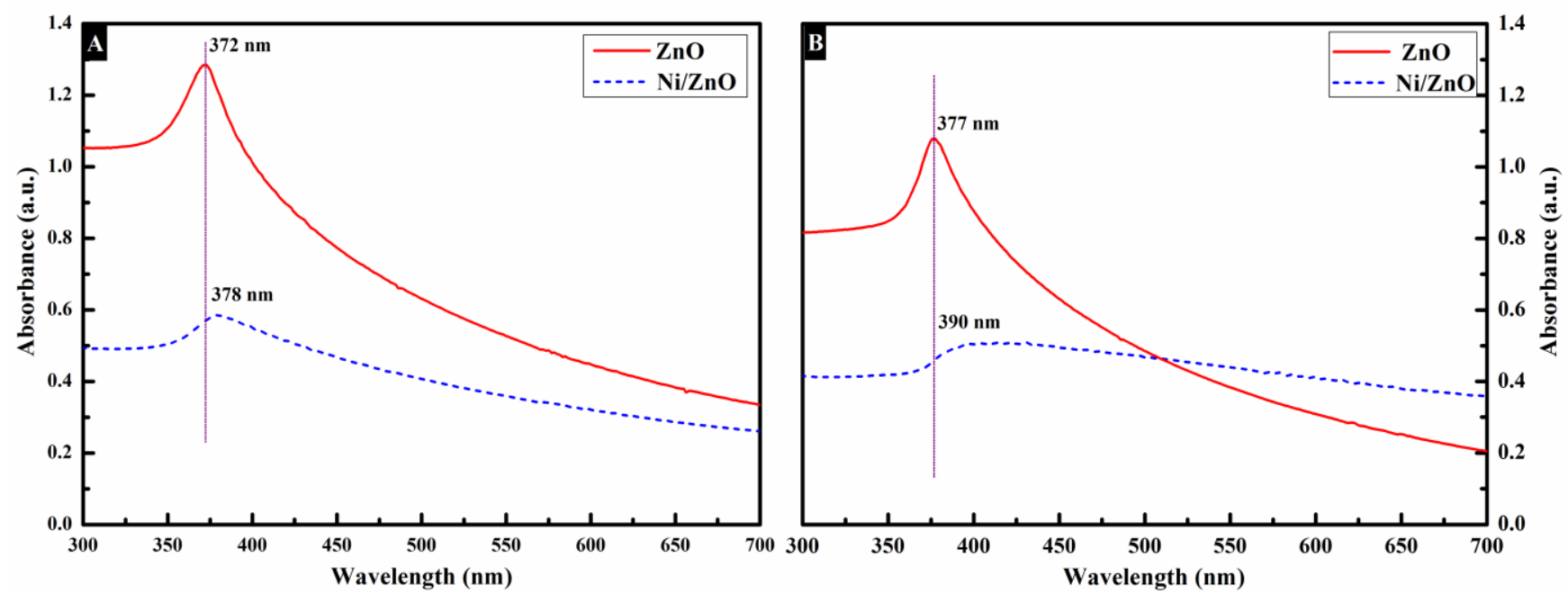

Figure 4 UV spectra of pure and $\mathrm{Ni} / \mathrm{ZnO}$ synthesized by CPM (A) and HTM (B)

As displayed all the samples exhibit an optical absorption below $400 \mathrm{~nm}$ due to the surface state of $\mathrm{ZnO}$ [42]. The absorption peak appeared at about $372 \mathrm{~nm}$ and $377 \mathrm{~nm}$ for CPM and HTM ZnO samples, respectively (Table 3). On incorporation of nickel, the absorption peak shifted towards higher wavelength, which resulted in the decrease of bandgap energy. The peak was very broad with a red shift and this can be attributed to the defect states between valence band and conduction band $\left(\mathrm{O}_{2 \mathrm{p}} \rightarrow \mathrm{Zn}_{3 \mathrm{~d}}\right)$ [43] and higher scattering at the surfaces of nanorods [44]. The Ni doping in $\mathrm{ZnO}$ causes the slight tapering of bandgap for both the cases.

$\mathrm{ZnO}$ is a directband gap semiconductor, and therefore its absorption coefficient is related to the excitation energy

$$
\alpha h v=C\left(h v-E_{g}\right)^{1 / 2}
$$

where $\alpha$ is the absorption coefficient hv is the incident photon energy $\mathrm{C}$ is the constant and $\mathrm{E}_{\mathrm{g}}$ is the direct band gap in $\mathrm{eV}\left\{\left(\mathrm{E}_{\mathrm{exc}}=\mathrm{h} v\right)\right.$ by $\left.(\alpha \mathrm{h} v)^{2}=\mathrm{C}\left(\mathrm{h} v-\mathrm{E}_{\mathrm{g}}\right)\right\}$. To obtain the absorption onset, $(\alpha \mathrm{h} v)^{2}$ was plotted versus energy hv. Extrapolation of the linear part until its intersection with the hv axis gives the values of $E_{\mathrm{g}}$. By knowing the value of absorbance and wavelength from the data, the optical band gap of $\mathrm{ZnO}$ was estimated by Tauc's plot [45] and it is shown in table 3:

\begin{tabular}{|c|c|c|c|c|}
\hline \multirow{2}{*}{ Sample Name } & \multicolumn{2}{|c|}{$\begin{array}{c}\text { Absorption edge } \\
\text { (nm) }\end{array}$} & \multicolumn{2}{c|}{$\begin{array}{c}\text { Band gap } \\
\text { (eV) }\end{array}$} \\
\cline { 2 - 5 } & CPM & HTM & CPM & HTM \\
\hline Pure ZnO & 372 & 377 & 3.34 & 3.29 \\
\hline Ni/ ZnO & 378 & 390 & 3.29 & 3.19 \\
\hline
\end{tabular}

Table 3. Shows the absorption edge and bandgap of pure and $\mathrm{Ni} / \mathrm{ZnO}$ samples by CPM and HTM

\subsection{Photoluminescence}

Figure 5 shows the room temperature $\mathrm{PL}$ spectra of the pure and $\mathrm{Ni} / \mathrm{ZnO}$ nanoparticles assynthesized by CPM (A) and HTM (B). 
A. Chandrasekaran, T. Prasankumar, Sujin P Jose, K. Anitha, C. Ekstrum, J. M. Pearce, J. Mayandi. "Synthetic method dependent physicochemical properties and electrochemical performance of Ni doped ZnO”, Chemistry Select 2(28), 2017, pp. 9014-9023. doi:
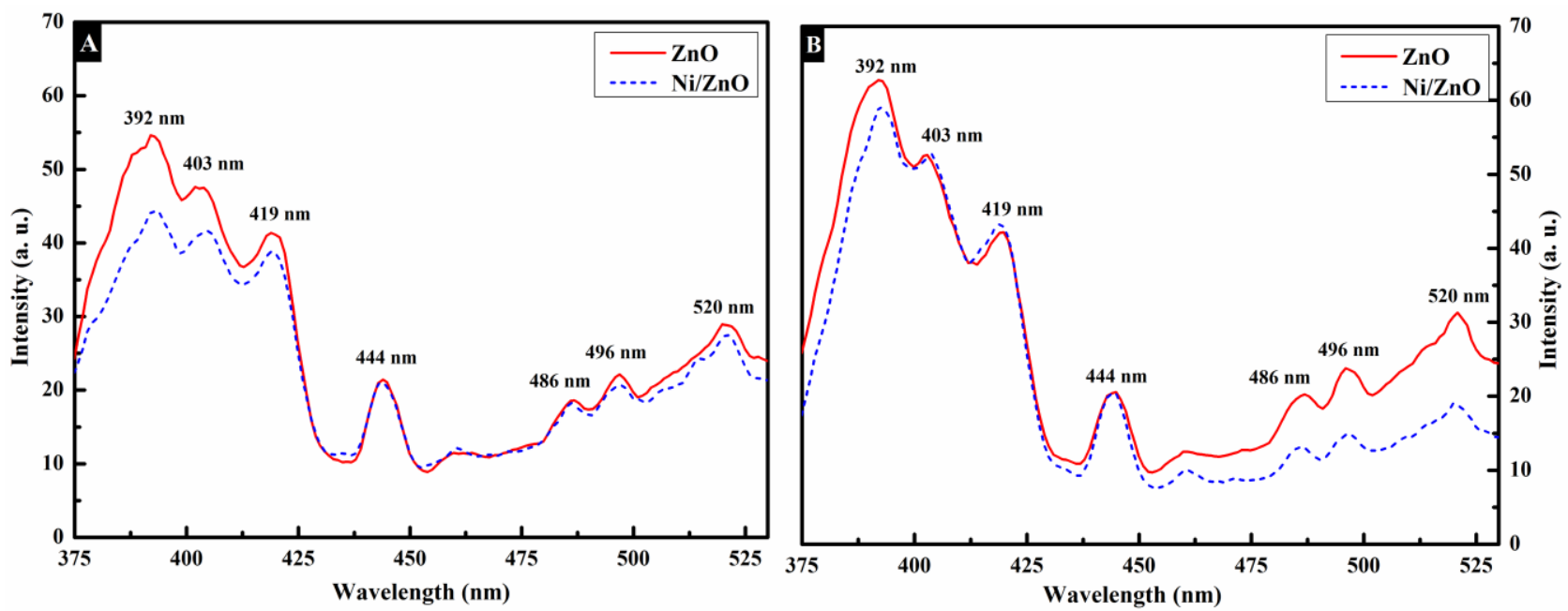

Figure 5 Emission spectra of pure and $\mathrm{Ni} / \mathrm{ZnO}$ synthesized by CPM (A) and HTM (B)

The PL measurements were performed at an excitation wavelength of $325 \mathrm{~nm}$. Excitonic emissions were observed from the photoluminescence spectra of $\mathrm{ZnO}$ nanomaterials. All the samples were optically similar with the emission peaks centered at $392 \mathrm{~nm}, 403 \mathrm{~nm}, 419 \mathrm{~nm}$ (violet emission), 444 $\mathrm{nm}$ (blue emission), $460 \mathrm{~nm}, 486 \mathrm{~nm}$ (blue green emission), $496 \mathrm{~nm}$ and $520 \mathrm{~nm}$ (green emission) irrespective of the method of preparation. The asymmetric spectra were due to the native defect states of $\mathrm{ZnO}$ [46]. The strong emission peak at $392 \mathrm{~nm}$ may be attributed to near band edge emission [47] and the peak at $403 \mathrm{~nm}$ was originated due to defect states [48]. Many researchers showed that the other visible emissions may be due to the zinc interstitials, zinc vacancies and oxygen vacancies [4951]. The oxygen vacancies were responsible for the green emission at $520 \mathrm{~nm}$ [52]. The intensity of emission mainly depends on surface states and the luminescence properties depend on the properties of the surface [53]. The strong UV and weak visible bands imply good crystal surface [54].

\subsection{FTIR}
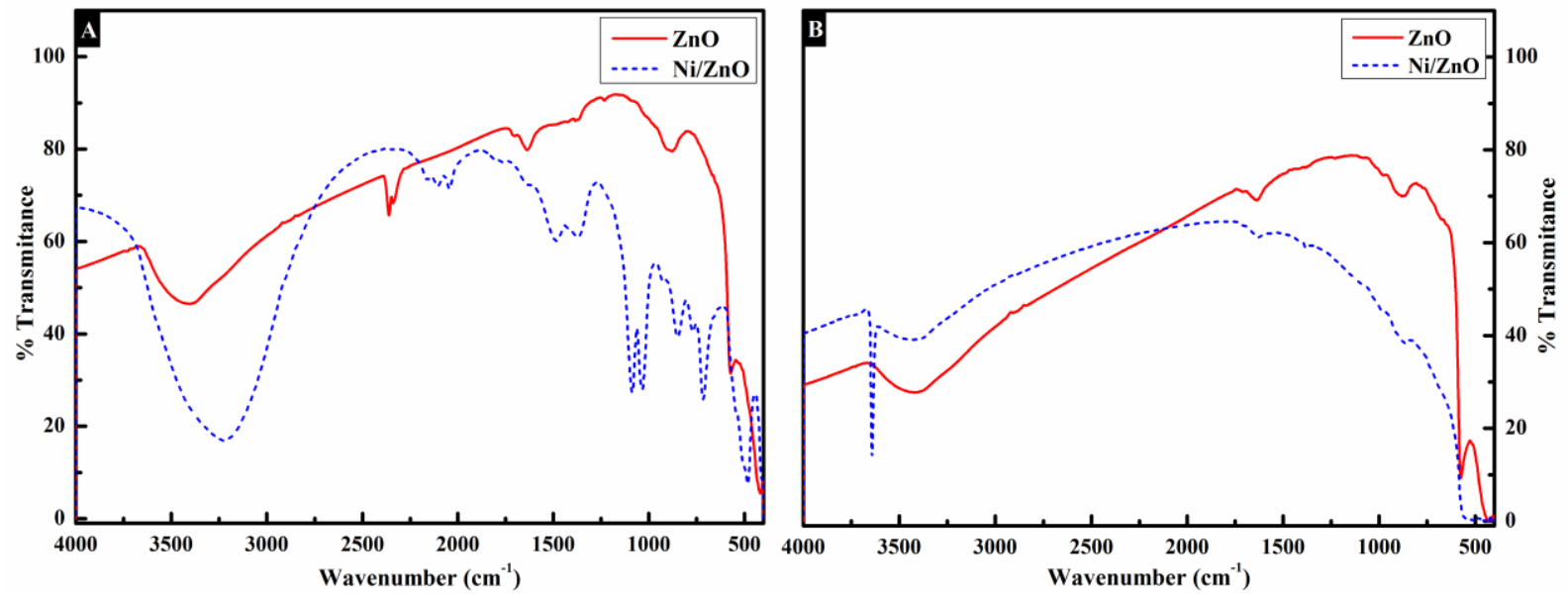

Figure 6 FTIR spectra of pure and $\mathrm{Ni} / \mathrm{ZnO}$ synthesized by CPM (A) and HTM (B)

Infrared spectroscopy was used to detect the presence of functional groups adsorbed on the surface of synthesized nanoparticle. FTIR spectra of pure $\mathrm{ZnO}$ and $\mathrm{Ni} / \mathrm{ZnO}$ synthesized by CPM and HTM methods are shown in Figure 6 (A \& B). In the co-precipitation method the broad absorption band at $3385 \mathrm{~cm}^{-1}$ corresponds to the $\mathrm{O}-\mathrm{H}$ stretching vibration of water present in $\mathrm{ZnO}$ [55] and the absorption peak at $2358 \mathrm{~cm}^{-1}$ is because of an existence of $\mathrm{CO}_{2}$ molecule present in the atmosphere [56]. In the hydrothermal method some slight changes are observed compared to co-precipitation method. The band at $1643 \mathrm{~cm}^{-1}(\mathrm{CPM})$ and the band at $1637 \mathrm{~cm}^{-1}$ (HTM) can be associated with the $\mathrm{H}-\mathrm{OH}$ stretching [57]. In the CPM method the transmission band at $\sim 1361 \mathrm{~cm}^{-1}$ the sample was due to 
A. Chandrasekaran, T. Prasankumar, Sujin P Jose, K. Anitha, C. Ekstrum, J. M. Pearce, J. Mayandi. "Synthetic method dependent physicochemical properties and electrochemical performance of Ni doped ZnO”, Chemistry Select 2(28), 2017, pp. 9014-9023. doi:

https://doi.org/10.1002/slct.201701584

the asymmetric stretching of acetate species from precursor [58] and this band was not observed in hydrothermally synthesized samples. The band appearing at $877 \mathrm{~cm}^{-1}$ in both the methods was due to the formation of tetrahedral co-ordination of $\mathrm{Zn}$ [59]. The peaks appearing between $400 \mathrm{~cm}^{-1}$ to 570 $\mathrm{cm}^{-1}$ were assigned to the Metal-Oxygen (M-O) stretching mode [60]. But in the case of $\mathrm{Ni}^{2+}$ more changes in peak intensity were observed. The vibration modes at $720 \mathrm{~cm}^{-1} \& 1086 \mathrm{~cm}^{-1}$ in CPM and $1430 \mathrm{~cm}^{-1}$ in HTM were associated with $\mathrm{Ni}^{2+}$ occupation at $\mathrm{Zn}^{2+}$ sites [61]. Because of ionic radii mismatch between $\mathrm{Ni}^{2+}$ intrinsic host lattice defects are activated. This type of activated impurity causes a shift in the vibration mode [62].

\subsection{Raman Spectroscopy}

The vibrational modes of $\mathrm{ZnO}$ might be changed by dopants, so Raman spectra of pure $\mathrm{ZnO}$ by CPM (A), Ni/ZnO by CPM (B), Pure ZnO by HTM (C) and Ni/ZnO by HTM (D) were measured and shown in Figure 7.
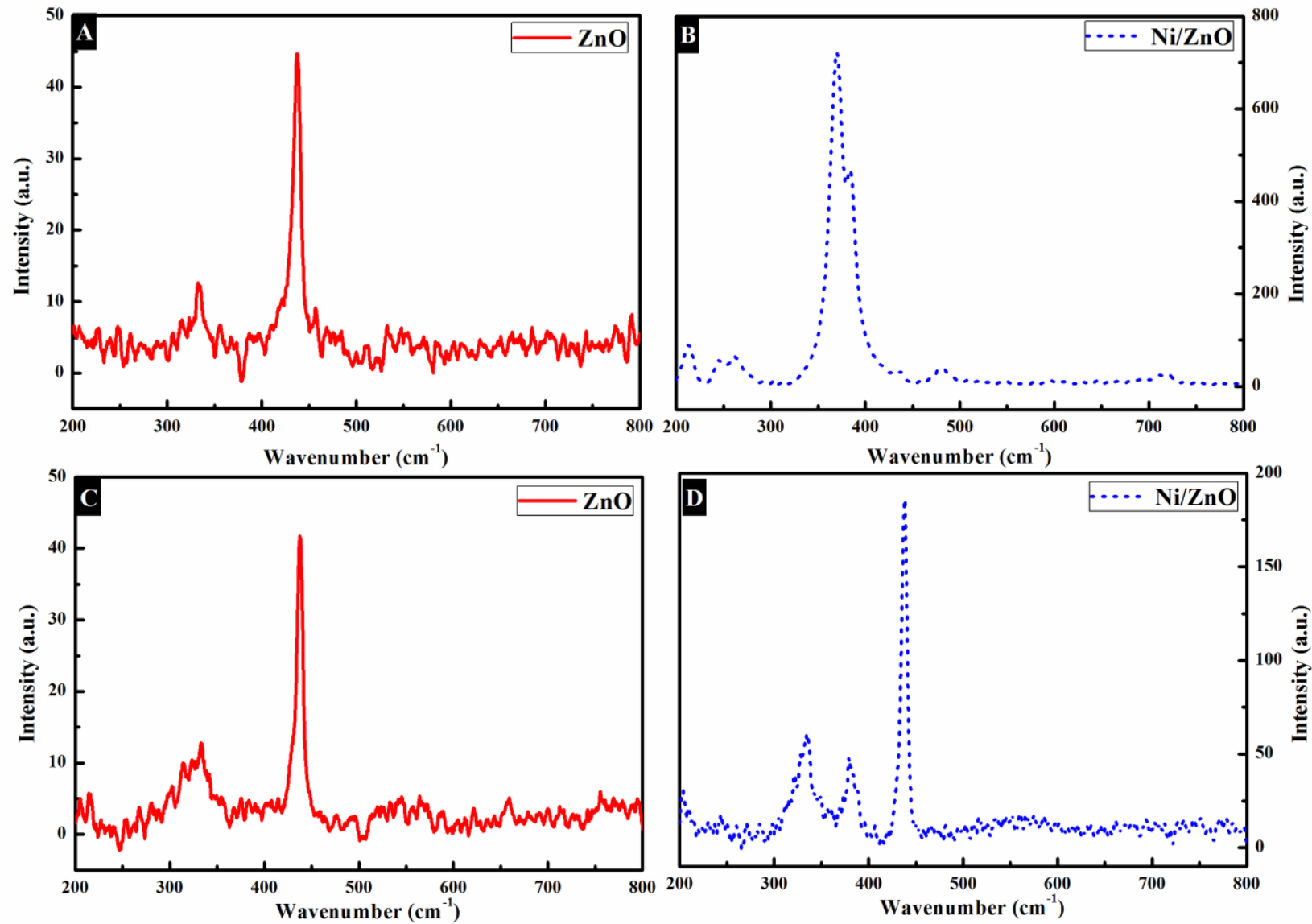

Figure 7 Raman spectra of pure $\mathrm{ZnO}$ by CPM (A), Ni/ZnO by CPM (B), Pure $\mathrm{ZnO}$ by HTM (C) and $\mathrm{Ni} / \mathrm{ZnO}$ by HTM (D)

Typically there are two polar branches, one non polar branch and eight sets of optical phonon modes in wurtzite $\mathrm{ZnO}$ crystal. The polar branches $\mathrm{A}_{1}$ and $\mathrm{E}_{1}$ split into longitudinal (LO) and transverse (TO) optical components with different frequencies. The non polar branch $\mathrm{E}_{2}$ contains low and high frequency phonons $\left(\mathrm{E}_{2 \mathrm{~L}}\right.$ and $\left.\mathrm{E}_{2 \mathrm{H}}\right)$ [63]. In which $\mathrm{E}_{2 \mathrm{~L}}$ is associated to the heavy zinc sublattice and $\mathrm{E}_{2 \mathrm{H}}$ associated only with oxygen atoms [64]. The phonon modes near the center of the Brillion zone $(\mathrm{G}$ point) may be written as: $\Gamma=\mathrm{A}_{1}+2 \mathrm{~B}_{1}+\mathrm{E}_{1}+2 \mathrm{E}_{2}$. Among these modes, $\mathrm{A}_{1}, \mathrm{E}_{1}$ and $2 \mathrm{E}_{2}$ are Raman active and $2 \mathrm{~B}_{1}$ is Raman inactive or forbidden mode for $\mathrm{ZnO}$ [65]. It is observed that the peak at $331 \mathrm{~cm}^{-1}$ and an intense peak at $438 \mathrm{~cm}^{-1}$ were consistent with $\mathrm{A}_{1}(\mathrm{TO})$ and $\mathrm{E}_{2}$ (high) vibration modes. For $\mathrm{Ni} / \mathrm{ZnO}$, an peak at $372 \mathrm{~cm}^{-1}(\mathrm{CPM})$ and $379 \mathrm{~cm}^{-1}$ (HTM) was observed and assigned to $\mathrm{E}_{2}$ (high)$\mathrm{E}_{2}$ (low) modes [66]. It can be seen that there was a blue shift with additional peaks located for the $\mathrm{Ni} / \mathrm{ZnO}$ by CPM due to the lattice-host intrinsic defect. The breakdown of translational crystal 
A. Chandrasekaran, T. Prasankumar, Sujin P Jose, K. Anitha, C. Ekstrum, J. M. Pearce, J. Mayandi. "Synthetic method dependent physicochemical properties and electrochemical performance of Ni doped ZnO”, Chemistry Select 2(28), 2017, pp. 9014-9023. doi:

https://doi.org/10.1002/slct.201701584

symmetry in the samples produced by co precipitation method was because of the incorporated defects and impurities. This indicates that that the $\mathrm{ZnO}$ was damaged, but still retains its wurtzite lattice structure.

\subsection{Electrochemical Characterizations Cyclic Voltammetry}
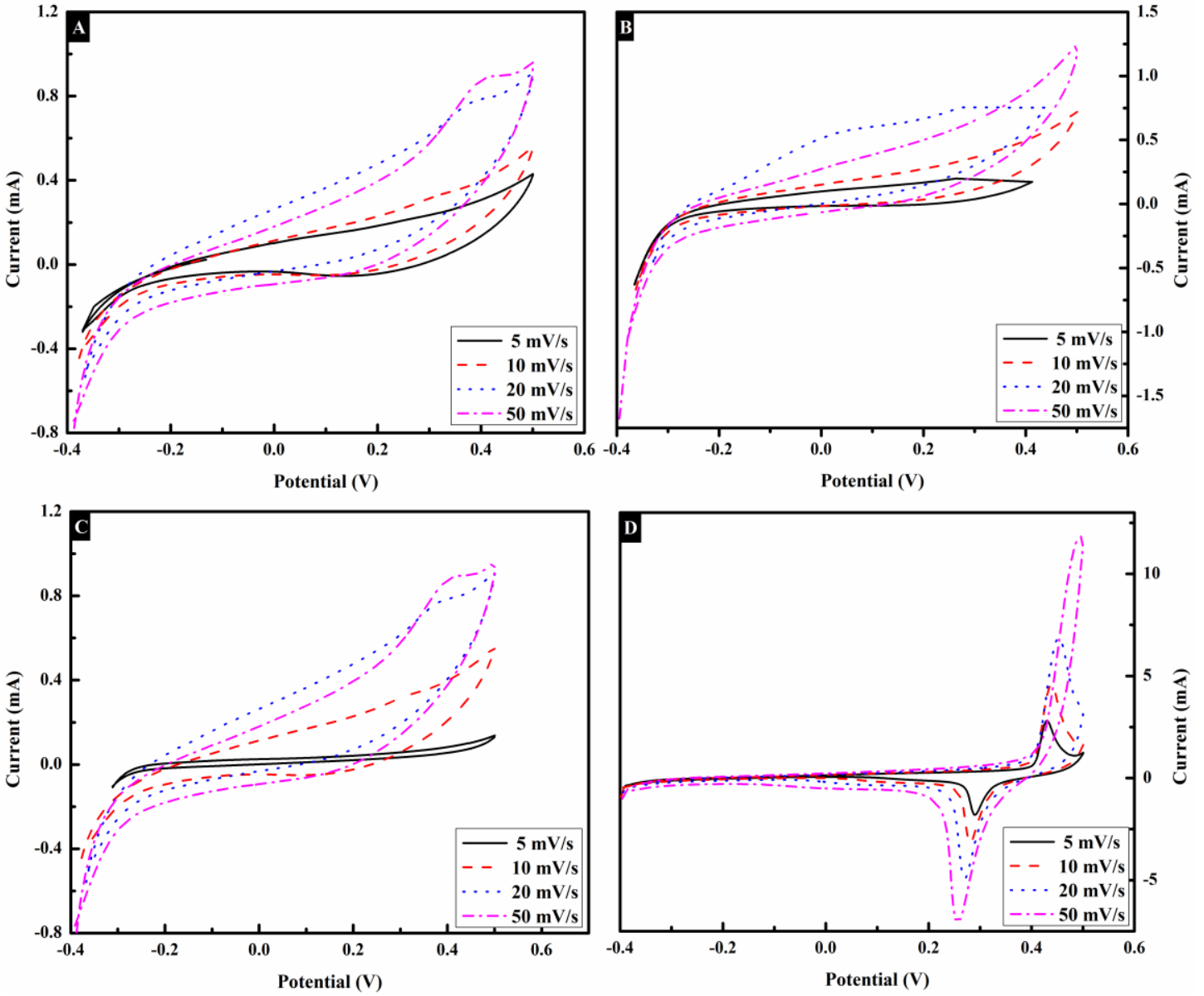

Figure 8. Cyclic Voltammograms of pure $\mathrm{ZnO}$ by CPM (A), Ni/ZnO by CPM (B), Pure ZnO by HTM (C) and $\mathrm{Ni} / \mathrm{ZnO}$ by HTM (D) at scan rates $5,10,20$ and $50 \mathrm{mV} / \mathrm{s}$.

Figure 8 shows the cyclic voltammograms of bare and $\mathrm{Ni} / \mathrm{ZnO}$ electrodes by CPM (A, B) and HTM $(\mathrm{C}, \mathrm{D})$ in $1 \mathrm{M} \mathrm{KOH}$ recorded at the scan rates of $5,10,20$, and $50 \mathrm{mV} / \mathrm{s}$. The cyclic voltammetry of the electrode materials were performed between the potential windows of $-0.4 \mathrm{~V}$ to $0.5 \mathrm{~V}$. All the samples exhibit quasi-rectangular like shape, reversible and capacitive behaviour. By changing the scan rate, the power properties of the electrodes were evaluated and the results are shown in Figure 8. It can be seen from the $\mathrm{CV}$ curves that the scan rate and the current response were directly proportional. For the pure and $\mathrm{Ni} / \mathrm{ZnO}$ by $\mathrm{CPM}$ and $\mathrm{HTM}$ it was observed that the $\mathrm{Ni} / \mathrm{ZnO}$ has better capacitive current. The Ni/ZnO electrode by HTM shows a pair of Faradaic redox peaks with high capacitive current $(\sim 12 \mathrm{~mA})$ comparing all other electrodes. These redox peaks were formed due to the intercalation and de-intercalation of $\mathrm{K}^{+}$ions from the electrolyte into $\mathrm{ZnO}$. The energy storage in these electrodes is due the accumulation of ionic charge in the double layer at the electrode/electrolyte interface. This implies that, of all the samples $\mathrm{Ni} / \mathrm{ZnO}$ (HTM) electrode has good capacitive performance which may be due to pseudo-capacitance of the electrochemically active $\mathrm{ZnO}$ nanorods, fast reversible redox reaction and effective electrical and ionic conductivity of $\mathrm{Ni}^{2+}$ and $\mathrm{Zn}^{2+}$.

\section{Galvanostatic Charge Discharge of Ni/ZnO Electrodes}


A. Chandrasekaran, T. Prasankumar, Sujin P Jose, K. Anitha, C. Ekstrum, J. M. Pearce, J. Mayandi. "Synthetic method dependent physicochemical properties and electrochemical performance of Ni doped ZnO”, Chemistry Select 2(28), 2017, pp. 9014-9023. doi:

https://doi.org/10.1002/slct.201701584

The charge-discharge measurements for bare and $\mathrm{Ni} / \mathrm{ZnO}$ electrodes by CPM (A, B) and HTM (C, D) were carried out using chronopotentiometry at different current densities in the potential window of $-0.4 \mathrm{~V}$ to $0.5 \mathrm{~V}$ and the corresponding results were shown in Figure 9.
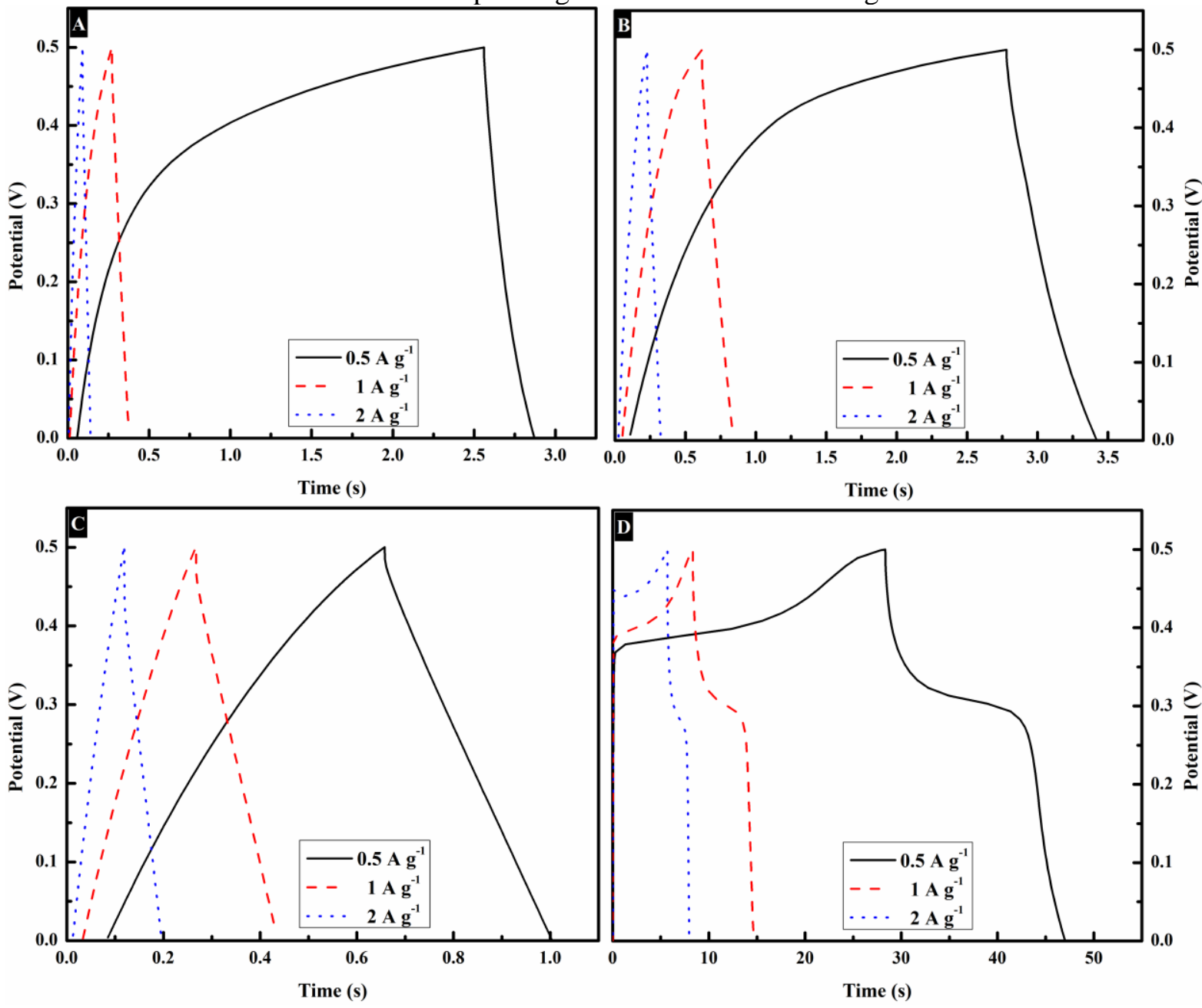

Figure 9 Galvanostatic charge-discharge curves of pure $\mathrm{ZnO}$ by $\mathrm{CPM}(\mathrm{A}), \mathrm{Ni} / \mathrm{ZnO}$ by $\mathrm{CPM}$ (B), Pure ZnO by HTM (C) and Ni/ZnO by HTM (D) hybrid electrode at different current densities.

The charge-discharge properties of $\mathrm{ZnO}$ electrodes in $1 \mathrm{M} \mathrm{KOH}$ were investigated with different current densities of $0.5,1$ and $2 \mathrm{~A} \mathrm{~g} \mathrm{~g}^{-1}$. The charge and discharge curves exhibit excellent reversibility for forward and backward reaction processes. A pseudo-capacitance behaviour of $\mathrm{ZnO}$ was observed for pure and $\mathrm{Ni} / \mathrm{ZnO}$ by CPM. Meanwhile, it should be noted that the curves for pure $\mathrm{ZnO}$ by HTM shows a nearly linear relationship, which is an ideal capacitive behaviour. The voltage decreases linearly with the increase of discharge time. A nonlinear double-layered discharge curve was obtained for $\mathrm{Ni} / \mathrm{ZnO}$ by HTM with increased capacitance. This may be due to defect rich nickel and zinc oxide and electrochemical adsorption-desorption or redox reaction at the electrode and electrolyte interface. The average specific capacitance of the electrodes can be calculated using the formula (equation 3):

$$
\mathbf{C}_{\mathrm{m}}=\mathbf{I t} / \Delta \mathbf{V}_{\mathrm{m}}
$$

where, $\mathrm{C}_{\mathrm{m}}, \mathrm{I}, \mathrm{t}$ and $\Delta \mathrm{V}$ are the specific capacitance of electrodes $\left(\mathrm{F} \mathrm{g}^{-1}\right)$, the charge-discharge current (A), the discharge time (s) and the mass of electrode, respectively.

Due to the incorporation of $\mathrm{Ni}$ as extrinsic impurity into the zinc oxide matrix, enormous oxygen vacancies were generated which leads empty oxygen sites. Thus the interstitial occurrence of zinc and Ni ions will promotes the ionic conductivity. This may leads to have either shallow or deep level donors in the bandgap of $\mathrm{ZnO}$. In the present investigation the results show that the preparation condition of the composite electrodes by the hydrothermal method helps in getting high defect 
A. Chandrasekaran, T. Prasankumar, Sujin P Jose, K. Anitha, C. Ekstrum, J. M. Pearce, J. Mayandi. "Synthetic method dependent physicochemical properties and electrochemical performance of Ni doped ZnO”, Chemistry Select 2(28), 2017, pp. 9014-9023. doi:

https://doi.org/10.1002/slct.201701584

content of zinc oxide with nickel, in increasing charge carriers, and enhancing double layer capacitance.

\section{Conclusions}

This study compares two different types of synthesis of $\mathrm{Ni} / \mathrm{ZnO}$ using the co-precipitation and hydrothermal methods. CPM provides an inexpensive route to the synthesis of many nanoparticle materials, but it lacks the reaction control needed for high quality crystallinity and purity of the materials. These challenges were overcome with the use of the hydrothermal method. In the UV optical analysis the HTM samples were slightly shifted towards the visible region when compared to CPM samples, which is due to the generation of more absorption states or defect energy bands. In the emission, both the samples have similar defect peaks with only change in intensity. In FTIR analysis it is observed that the transmission band for the carbonyl group of the carboxylate ions was absent in HTM samples, which shows that the precursor peaks were removed by the hydrothermal condition. Raman analysis also showed that the HTM samples have defect free crystallinity. The CV curve suggests that the electrochemical capacitance performances of the $\mathrm{Ni} / \mathrm{ZnO}$ by HTM are good with highest current density than by CPM. The discharge curves are linear in the total range of potential with constant slopes, showing perfect capacitive behaviour for $\mathrm{Ni}$ doped sample prepared by hydrothermal synthesis. In conclusion, the electrodes fabricated using HTM shows good efficiency when compared to the samples prepared with the co-precipitation method. These preliminary findings open up new opportunities for $\mathrm{Ni} / \mathrm{ZnO}$ nanoparticles in applications of electrochemical supercapacitors as well as other energy storage devices. $\mathrm{Ni} / \mathrm{ZnO}$ nanoparticles synthesized by this method with further optimization have the potential to lead to a high-efficiency supercapacitors.

\section{Acknowledgement}

AC thanks the DST-INSPIRE New Delhi, India for the financial assistance as fellowship. JM, thanks the DST-SERB for the partial support through the project SERB/F/1829/2012-13. JM and SPJ thank UGC, New Delhi, INDIA for providing support through RAMAN fellowship (2014-2015). SPJ, wishes to acknowledge UGC-MRP programme for providing financial support through the project F.No. 42-793/2013 (SR). CE and JMP thank the MacArthur Fellowship for support.

\section{References}

1. E. Kaidashev, M. Lorenz, H. Von Wenckstern, A. Rahm, H.C.Semmelhack, K. H. Han, G. Benndorf, C. Bundesmann, H. Hochmuth, M. Grundmann, High electron mobility of epitaxial ZnO thin films on c-plane sapphire grown by multi step pulsed-laser deposition, Appl. Phys. Lett., 82 (2003) 3901-3903.

2. F. Pirot, J. Millet, Y.N. Kalia, P. Humbert, In vitro study of percutaneous absorption, cutaneous bioavailability and bioequivalence of zinc and copper from five topical formulations, Skin Pharmacol., 9 (1996) 259-269.

3. Z.H. Lim, Z.X. Chia, M. Kevin, A.S.W. Wong, G.W. Ho, A facile approach towards ZnO nanorods conductive textile for room temperature multifunctional sensors, Sens. Actuators B Chem. , 151 (2010) 121-126.

4. M. Purica, E. Budianu, E. Rusu, ZnO thin film on semiconductors materials substrate for large area photo-detector applications, Thin Solid Films, 383 (2001) 284-286.

5. S.H. Jo, J.Y. Lao, Z.F. Ren, R.A. Farrer, T. Baldacchini, J.T. Fourkas, Field-emission studies on thin films of zinc oxide nanowires, Appl. Phys. Lett., 83 (2003) 4821-4823.

6. F.C. Lin, Y. Takao, Y. Shimizu, M. Egashira, Hydrogen-Sensing mechanism of Zinc-oxide varistor gas sensors, Sens. Actuators B Chem., 24 (1995) 843-850.

7. M. Wang, X. Wang, Electrodeposition zinc-oxide inverse opal and its application in hybrid photovoltaics, Sol. Energy Mater. Sol. Cells, 92 (2008) 357-362.

$8 . \quad$ L. Liao, H.B. Lu, M. Shuai, J.C. Li, Y.L. Liu, C. Liu, Z.X. Shen and T. Yu, A novel gas sensor based on field ionization from $\mathrm{ZnO}$ nanowires: moderate working voltage and high stability, Nanotechnology, 19 (2008) 175501-175506.

9. M. Li, H. Bala, X. Lv, X. Ma, F. Sun, L. Tang, Z. Wang, Direct synthesis of monodispersed $\mathrm{ZnO}$ nanoparticles in an aqueous solution, Mater. Lett., 61 (2007) 690-693. 
A. Chandrasekaran, T. Prasankumar, Sujin P Jose, K. Anitha, C. Ekstrum, J. M. Pearce, J. Mayandi. "Synthetic method dependent physicochemical properties and electrochemical performance of Ni doped ZnO”, Chemistry Select 2(28), 2017, pp. 9014-9023. doi:

https://doi.org/10.1002/slct.201701584

10. V. Cracium, J. Elders, JGE. Gardeniers, J. Geretovsky, Ian W. Boyd, Growth of ZnO thin films on GaAs by pulsed laser deposition. Thin Solid Films, 259 (1995) 1-4.

11. M.H. Huang, Y. Wu, H. Feick, N. Tran, E. Weber, P. Yang, Catalytic growth of zinc oxide nanowires by vapor transport, Adv. Mater., 13 (2001) 113-116.

12. H. Yu, Z. Zhang, M. Han, X. Hao, F. Zhu, A general low-temperature route for large-scale fabrication of highly oriented $\mathrm{ZnO}$ nanorod/nanotube arrays, J. Am. Chem. Soc., 127 (2005) 23782379.

13. I. Gonzalez-Valls, Y. Yu, B. Ballesteros, J. Oro, M. Lira-Cantu, Synthesis conditions, light intensity and temperature effect on the performance of $\mathrm{ZnO}$ nanorods-based dye sensitized solar cells, J. Power Sources, 196 (2011) 6609-6621.

14. Z.W. Pan, Z.R. Dai, Z.L. Wang, Nanobelts of semiconducting oxides, Science, 291 (2001) 1947-1956.

15. X.Y. Kong, Y. Ding, R.S. Yang, Z.L. Wang, Single-crystal nanorings formed by epitaxial self-coiling of polar nanobelts, Science, 303 (2004) 1348-1351.

16. X.Y. Kong, Z.L. Wang, Spontaneous polarization-induced nanohelixes, nanosprings, and nanorings of piezoelectric nanobelts, Nano Lett., 3 (2003) 1625-1631.

17. Z.L. Wang, X.Y. Kong, J.M. Zuo, Induced growth of asymmetric nanocantilever arrays on polar surfaces, Phys. Rev. Lett., 91 (2003) 185502-185506.

18. Parasharam M. Shirage, ZnO nano-flowers, Materials Today, 16 (2013) 505-506.

19. M. Prabhu, J. Mayandi, R.N. Mariammal, V. Vishnukanthan, J.M. Pearce, , N. Soundararajan, K. Ramachandran, Peanut shaped $\mathrm{ZnO}$ microstructures: controlled synthesis and nucleation growth toward low-cost dye sensitized solar cells, Materials Research Express, 2 (2015) 066202-066208.

20. C. Chen, P. Liu, C. Lu, ZnO nano-flowers, Chem. Eng. J., 144 (2008) 509-513.

21. O.D. Jayakumar, H.G. Salunke, R.M. Kadam, M. Mohapatra, G. Yashwant,

S.K. Kulshreshtha, Magnetism in Mn-doped $\mathrm{ZnO}$ nanoparticles prepared by a co-precipitation method, Nanotechnology, 17 (2006) 1278-1285.

22. Th. Agne, Z. Guan, X.M. Li, H. Wolf, Th. Wichert, H. Natter, R. Hempelmann, Doping of the nanocrystalline semiconductor zinc oxide with the donor indium, Appl. Phys. Lett., 83 (2003) 1204-1207.

23. S. Ameen, M.S. Akhtar, H.K. Seo, Y.S. Kim, H.S. Shin, Influence of Sn doping on ZnO nanostructures from nanoparticles to spindle shape and their photoelectrochemical properties for dye sensitized solar cells, Chem. Eng. J., 187 (2012) 351-356.

24. C.X. Xu, X.W. Sun, B.J.P. Chen, Field emission from gallium-doped zinc oxide nanofiber array, Appl. Phys. Lett., 84 (2004) 1540-1542.

25. Harvey, D., Modern Analytical Chemistry. McGraw-Hill, United States of America, 2000

26. C. N. R. Rao, A. Miller, A. K. Cheetham, The chemistry of Nanomaterials: Synthesis, Properties and Applications, Wiley- VCH Verlag GmbH \& Co. KGaA, 2004.

27. M. Rajamathi, R. Seshadri, Oxide and chalcogenide nanoparticles from hydrothermal/solvothermal reactions, Curr. Opin. Solid State Mater. Sci., 6 (2002) 337-345

28. S.J. Pearton, C.R. Abernathy, M.E. Overberg, G.T. Thaler, D.P. Norton, N. Theodoropoulou, A. F. Hebard, Y. D. Park, F. Ren, J. Kim, L. A. Boatner, Wide band gap ferromagnetic semiconductors and oxides. J. Appl. Phys., 93 (2003) 1-13.

29. F. Ahmed, N. Arshi, M.S. Anwar, S.H. Lee, E.S. Byon, N.J. Lyu, B.H. Koo, Effect of Ni substitution on structural, morphological and magnetic properties of $\mathrm{Zn1-xNixO}$ nanorods, Curr. Appl. Phys., 12 (2012) 174-177.

30. J. Bae, M. K. Song, Y. J. Park, J. M. Kim, M. Liu, and Z. L. Wang, Fiber Supercapacitors Made of Nanowire-Fiber Hybrid Structures for Wearable/Flexible Energy Storage, Angew. Chem. Int. Ed. 50 (2011) 1683-1687.

31. A. Burke, Ultracapacitors: why, how, and where is the technology, Journal of Power Sources, $91(2000)$ 37-50.

32. M. Selvakumar, D. Krishna Bhat, A. Manish Aggarwal, S. Prahladh Iyer, G. Sravani, Nano ZnO-activated carbon composite electrodes for supercapacitors, Physica B, 405 (2010) 2286-2289. 
A. Chandrasekaran, T. Prasankumar, Sujin P Jose, K. Anitha, C. Ekstrum, J. M. Pearce, J. Mayandi. "Synthetic method dependent physicochemical properties and electrochemical performance of Ni doped ZnO”, Chemistry Select 2(28), 2017, pp. 9014-9023. doi:

https://doi.org/10.1002/slct.201701584

33. T. Prasankumar, V. S. Irthaza Aazem, P. Raghavan, K. Prem Ananth, S.Biradar, R. Ilangovan and Sujin Jose, Microwave assisted synthesis of 3D network of $\mathrm{Mn} / \mathrm{Zn}$ bimetallic oxide-high performance electrodes for supercapacitors, J. Alloys Comp., 695 (2017) , 2835-2843 .

34. D. Kalpana, K.S. Omkumar, S. Suresh Kumar, N.G. Renganathan, A novel high power symmetric $\mathrm{ZnO} /$ carbon aerogel composite electrode for electrochemical supercapacitor, Electrochimica Acta, 52 (2006) 1309-1315.

35. Sato K, Katayama-Yoshida H. Stabilization of ferromagnetic states by electron doping in $\mathrm{Fe}$-, Co- or Ni-doped ZnO. Jpn J Appl Phys., 40 (2001) 334-340.

36. C. Cheng, G. Xu, H. Zhang, Y. Luo., Hydrothermal synthesis Ni-doped ZnO nanorods with room-temperature ferromagnetism. Mater Lett., 62 (2008) 1617-1620.

37. M.El-Hilo, A.A. Dakhel, A.Y. Ali-Mohamed, Room temperature ferromagnetism in nanocrystalline Ni-doped $\mathrm{ZnO}$ synthesized by co-precipitation, J Magn Magn Mater, 321 (2009) 2279-2283.

38. X. Xu, C. Cao, Hydrothermal synthesis and magneto-optical properties of Ni-doped $\mathrm{ZnO}$ hexagonal columns, J Magn Magn Mater, 377 (2015) 308-313.

39. M. U. Ibezim-Ezeani, F. A. Okoye, O. Akaranta, Kinetic studiem on the removal of some metal ions from aqueous solution using modified Orange mesocarp extract, Int. J. Water Res. Environ. Eng., 4 (2012) 192-200.

40. P. Amornpitoksuk, S. Suwanboon, S. Sangkanu, A. Sukhoom, N. Muensit, J. Baltrusaitis, Synthesis, characterization, photocatalytic and antibacterial activities of Ag-doped ZnOpowders modified with a diblock copolymer, Powder Technol., 219 (2012) 158-164.

41. Y. Caglar, S. Aksoy, S. Ilican, M. Caglar, Crystalline structure and morphological properties of undoped and Sn doped ZnO thin films, Superlattices Microstruct., 46 (2009) 469-475.

42. J. Cui, D. Wang, T. Xie, Y. Lin., Study on photoelectric gas-sensing property and photogenerated carrier behavior of $\mathrm{Ag}-\mathrm{ZnO}$ at the room temperature, Sens Actuators B Chem.., 186 (2013) 165-171.

43. T. Sahoo, M. Kim, J. H. Baek, S. R. Jeon, J. S. Kim, Y. T. Yu, C. R. Lee, I. H. Lee, Synthesis and characterization of porous $\mathrm{ZnO}$ nanoparticles by hydrothermal treatment of as pure aqueous precursor, Mater Research Bull., 46 (2011) 525-530.

44. A. Escobedo Morales, M. Herrera Zaldivar, U. Pal., Indium doping in nanostructured $\mathrm{ZnO}$ through low-temperature hydrothermal process, Optical Materials, 29 (2006) 100-104.

45. K. Prabakar, S. Venkatachalam, Y.L. Jeyachandran, S.K. Narayandass, D. Mangalaraj., Microstructure, Raman and optical studies on Cd 0.6 Zn 0.4 Te thin films, Mater. Sci. Eng. B., 107 (2004) 99-105.

46. S. K. Mishra, S. Bayan, R. Shankar, P. Chakraborty, R. K. Srivastava., Efficient UV photosensitive and photoluminescence properties of sol-gel derived $\mathrm{Sn}$ doped $\mathrm{ZnO}$ nanostructures, Sensor Actuat A-Phys., 211 (2014) 8-14.

47. M. Ahmad, J. Zhao, J. Iqbal, W. Miao, L. Xie, R. Mo, J. Zhu, Conductivity enhancement by slight indium doping in $\mathrm{ZnO}$ nanowires for optoelectronic applicationsJ. Phys. D: Appl. Phys., 42 (2009) 165406-165413.

48. S.W. Xue, X.T. Zu, L.X. Shao, Z.L. Yuan, W.G. Zheng, X.D. Jiang, H. Deng, Effects of annealing on optical properties of Zn-implanted ZnO thin films, J. Alloys Compd., 458 (2008) 569573.

49. K. Vanheusden, W.L. Warren, C.H. Seager, D.R. Tallant, J.A. Voigt, B.E. Gnade, Mechanisms behind green photoluminescence in $\mathrm{ZnO}$ phosphor powders, J.Appl. Phys., 79 (1996) 7983-7990.

50. G. Xiong, U. Pal, J.G. Serrano, Correlations among size, defects, and photoluminescence in ZnO nanoparticles, J. Appl. Phys., 101 (2007) 024317-024323.

51. U. Pal, P. Santiago, Controlling the morphology of $\mathrm{ZnO}$ nanostructures in a low-temperature hydrothermal process, J. Phys. Chem. B, 109 (2005) 15317-15321.

52. M. Liu, A.H. Kitai, P. Mascher, Point defects and luminescence centres in zinc oxide and zinc oxide doped with manganese, J. Lumin., 54 (1992) 35-42.

53. I. Shalish, H. Temkin, V.Narayanamurti, Size-dependent surface luminescence in $\mathrm{ZnO}$ nanowires. Phys. Rev., 69 (2004) 1-4. 
A. Chandrasekaran, T. Prasankumar, Sujin P Jose, K. Anitha, C. Ekstrum, J. M. Pearce, J. Mayandi. "Synthetic method dependent physicochemical properties and electrochemical performance of Ni doped ZnO”, Chemistry Select 2(28), 2017, pp. 9014-9023. doi:

https://doi.org/10.1002/slct.201701584

54. W. E. Mahmoud, Synthesis and optical properties of Ce-doped $\mathrm{ZnO}$ hexagonal nanoplatelets, J. Cryst. Growth, 312 (2010) 3075-3079.

55. R. Georgekutty, M. K. Seery and S. C. Pillai, A highly efficient Ag-ZnO photocatalyst: synthesis, properties, and mechanism, J. Phys. Chem. C, 112 (2008) 13563-13570.

56. M. Arshad, A. Azam, A. S. Ahmed, S. Mollah, A. H. Naqvi, Effect of Co substitution on the structural and optical properties of $\mathrm{ZnO}$ nanoparticles synthesized by sol-gel route, J. Alloys Comp., 509 (2011) 8378-8381.

57. X. Sui, Y. Liu, C. Shao, Y. Liu, C. Xu, Structural and photoluminescent properties of ZnO hexagonal nanoprisms synthesized by microemulsion with polyvinyl pyrrolidone served as surfactant and passivant, Chem. Phys. Lett., 424 (2006) 340-344.

58. C. P. Sibu, S. R. Kumar, P. Mukundan, K. G. K. Warrier, Structural modifications and associated properties of lanthanum oxide doped sol-gel nanosized titanium oxide, Chem. Mater., 14 (2002) 2876-2881.

59. K. Ravichandrika, P. kiranmayi, R. V. S. S. N. Ravikumar, Synthesis,characterization and antibacterial activity of ZnO nanoparticles, Int J Pharm Pharm Sci, 4 (2012) 336-338.

60. U. Ozgür, Y. I. Alivov, C. Liu, A. Teke, M.A. Reshchikov, S. Dogan, V. Avrutin, S.J. Cho, H. Morkoc, A comprehensive review of $\mathrm{ZnO}$ materials and devices, J. Appl. Phys., 98 (2005) 041301-041404.

61. R. Saravanan, Kalavathy Santhi, N. Sivakumar, V. Narayanan, A. Stephen, Synthesis and characterization of $\mathrm{ZnO}$ and $\mathrm{Ni}$ doped $\mathrm{ZnO}$ nanorods by thermal decomposition method for spintronics application, Mater. Charact., 67 (2012) 10-16.

62. C.K. Ghosh, S. Malkhandi, M.K. Mitra, K.K. Chattopadhyay. Effect of Ni doping on the dielectric constant of $\mathrm{ZnO}$ and its frequency dependent exchange interaction, J Phys D: Appl Phys., 41 (2008) 245113-245119.

63. T.C.Damen, S.P.S.Porto, B.Tell, Raman effect in zinc oxide, Phys.Rev., 142 (1966) 570-574.

64. R.S. Zeferino, M.B. Flores, U. Pal, J. Appl. Phys., Photoluminescence and Raman Scattering in Ag-doped ZnO Nanoparticles, 109 (2011) 14308-14314.

65. J.M. Calleja, M. Cardona, Resonant Raman scattering in ZnO, Phys. Rev. B., 16 (1977) 3753-3761.

66. B. Yang, A. Kumar, N. Upia, P. Feng and R.S. Katiyar, Low-temperature synthesis and Raman scattering of Mn-doped ZnO nanopowders, J. Raman Spectrocs., 41 (2010) 88-92. 